TITLE:

\title{
Global Monitoring of Large Concrete Structures Using Acoustic Emission and Ultrasonic Techniques: Case Study
}

\section{$\operatorname{AUTHOR}(\mathrm{S})$ :}

Shiotani, Tomoki; Aggelis, Dimitrios G.; Makishima, Osamu

\section{CITATION:}

Shiotani, Tomoki ... [et al]. Global Monitoring of Large Concrete Structures Using Acoustic Emission and Ultrasonic Techniques: Case Study. Journal of Bridge Engineering 2009, 14(3): 188-192

\section{ISSUE DATE:}

2009-06

URL:

http://hdl.handle.net/2433/123385

\section{RIGHT:}

Copyright (C) 2009 American Society of Civil Engineers; この論文は出版 社版でありません。引用の際には出版社版をご確認ご利用ください。; This is not the published version. Please cite only the published version. 


\title{
Global monitoring of large concrete structures using acoustic emission and ultrasonic techniques: case study.
}

\author{
Tomoki Shiotani $^{1}$, Dimitrios G. Aggelis ${ }^{2}$ and Osamu Makishima ${ }^{3}$
}

\begin{abstract}
Global monitoring of civil structures is a demanding challenge for engineers. Acoustic Emission (AE) is one of the techniques that have the potential to inspect large volumes with transducers placed in strategic locations of the structure. In this paper, the AE technique is used to characterize the structural condition of a concrete bridge. The evaluation of AE activity leads to information about any specific part of the structure that requires attention. Consequently, more detailed examination can be conducted once the target area is selected. In this case, wave propagation velocity was used as a means to evaluate in more detail the condition of the region indicated by the AE analysis.
\end{abstract}

CE Database subject headings: acoustic techniques, concrete bridge, damage assessment, nondestructive tests, strain measurement, wave velocity.

\footnotetext{
${ }^{1}$ Associate Professor, Department of Urban Management, Graduate School of Engineering, Kyoto University C12-236, Kyoto-Katsura, Nishikyo-ku, Kyoto 615-8540, Japan, Tel: +81(0)75 383 3261, Fax: +81(0)75 3833264 , email: shiotani@toshi.kuciv.kyoto-u.ac.jp

${ }^{2} \mathrm{PhD}$ Research Fellow, Research Institute of Technology, Tobishima Corp., Kimagase 5472, Noda-shi, Chiba 270-0222, Japan. Currently Assistant Professor, Department of Materials Science and Engineering, University of Ioannina, Greece, Email: daggelis@cc.uoi.gr

${ }^{3}$ MSc, Civil Engineering Headquarters, Tobishima Corp., 2-Banchi, Sanbancho, Chiyoda-ku, Tokyo, 102-8332, Japan, email: osamu_makishima@tobishima.co.jp
} 


\section{INTRODUCTION}

The deterioration of civil infrastructure worldwide calls for effective methods for damage evaluation and repair. One of them, the Acoustic Emission (AE) monitoring technique, uses signals generated within the structure, which are due to crack growth under stress, to parameterize the fracture/failure process, as well as secondary emissions due to friction of crack interfaces. This unique monitoring mechanism distinguishes the technique from other nondestructive testing (NDT) methods and makes it the only one capable of real time mapping of fracture processes. In addition to real time source location of the captured AE events, the energy level or "magnitude" of the detected events, offers an evidence of the degree of damage provided that other sources of noise are excluded. A particular engineering advantage of the AE technique is its efficiency for global monitoring since a large and complex structure can be monitored with a limited number of sensors. Consecutively, the most sensitive part of the structure can be targeted with a more detailed AE monitoring for quantification of AE indices (Shiotani et al., 1994, Grosse et al., 1997, Ohtsu et al., 2002, Shiotani, 2006), or using other suitable techniques (Malhotra and Carino, 1991). Results obtained with AE depend on many parameters like the applied load and the loading rate, the properties of the material and the type of structure. These factors may restrict the selection of $\mathrm{AE}$ as an applicable tool for use in the field for those not familiar with the NDE technique. Additionally, due to the complex composition of most civil structures, AE waveforms depend on their propagation path from the source to the sensors (Schechinger and Vogel, 2007). However, in any case, valuable information can be extracted concerning which part of structure has sustained the most severe deterioration.

In the specific case presented herein, a $45 \mathrm{~m}$ bridge span was inspected. Preliminary visual inspection and testing of excavated cores did not reveal extensive damage. However, cores are 
characteristic only of the area where they were extracted and cannot be considered representative of the whole volume. Therefore, further monitoring was decided with AE technique. The stress was applied by the passing load of a heavy vehicle. A similar application of much smaller scale is mentioned in (Ohtsu et al., 2002). AE parameters were analyzed and the part of the structure more likely to exhibit higher damage degree was selected. An ultrasonic examination on the surface followed in order to extract the pulse velocity of concrete at that area, which is indicative of the quality (Naik and Malhotra, 1991, Gudra and Stawinski, 2000). The measured velocities were actually low, indicating questionable quality and confirmed the initial indication by $\mathrm{AE}$ activity.

\section{EXPERIMENTAL PROCEDURE}

For the AE monitoring, a total of 28 sensors were attached to the bottom surface of the bridge using electron wax. They were placed on the longitudinal axis of the bridge with separation of 1.5 m. The approximate locations are shown in Fig. 1. Specifically, the low frequency R6 from Physical Acoustics Corp. (PAC) were used. The R6 sensor has a resonant frequency of approximately $60 \mathrm{kHz}$ and is widely used for concrete. Before the test, pencil lead breaks were performed near each sensor and the results were within $1 \mathrm{~dB}$ margin at the top of the voltage range, showing that all transducers were adequately mounted. The detected AE signals were preamplified by $40 \mathrm{~dB}$ and acquired in two synchronized data acquisition systems, namely a 16channel DiSP and a 12-channel Mistras of PAC. Strain gauges were also placed in three locations of the top surface of the bridge, as shown in Fig. 1. 


\section{ACOUSTIC EMISSION ACTIVITY}

The load for the AE monitoring was supplied by a 20-ton crane, which passed over the bridge with a constant speed of approximately $0.5 \mathrm{~m} / \mathrm{s}$ (see Fig. 1). As the crane moved over the bridge, the strain on the top surface of the bridge at the mid-span was monitored and can be seen in Fig. 2. The maximum strain was recorded at $88 \mathrm{~s}$, when the truck was in the middle of the span, suggesting the highest tensile stress due to bending at the bottom layer of the structure, where the sensors were attached. In the same figure, the cumulative number of AE hits recorded by all the sensors is depicted for one passage. It can be seen that the rate of AE hits was more intensive before the crane reached the center of the bridge at $88 \mathrm{~s}$. Up to that moment more than $70 \%$ of the total number of hits was recorded, implying that more active sources were located in the first half of the bridge. In the same figure, the cumulative number of hits recorded only by the two sensors located close to the center of the bridge is depicted. For clarity reasons they are multiplied by a factor of 5 in the figure. The hits of these sensors started at $14 \mathrm{~s}$ before the crane reaches the middle point, and the last hit was recorded $10 \mathrm{~s}$ after the crane had passed over that point, showing again higher activity at the first half of the structure.

The interpretation of AE information is not always easy. This is the reason why different indices have been introduced. Some of them utilize the relative number of hits during the loading and unloading process, or the load at which the AE activity starts (Ohtsu et al., 2002, Colombo et al., 2005). Others take advantage of the amplitude distribution of AE events (Shiotani et al. 1994, Shiotani et al. 2007). However, in this case just the total number of hits during the crane passage sufficed the requirements of the test. The total number of hits recorded at each sensor during all the passages of the crane is depicted in Fig. 3. The position of each sensor is indicated by the axis on the top of the figure. It is certain that the first part before $20 \mathrm{~m}$, exhibited highest rate of 
emissions. Specifically, channel \#10 recorded the highest number of hits. This corresponds to the distance of $14 \mathrm{~m}$ from the starting point. It is well known that the AE activity is connected to the extent of damage through primary (crack growth) and secondary (frictions) mechanisms. Therefore, the area near the sensor which recorded the highest activity was the most likely to have sustained more serious damage than the rest of the structure examined. Consecutively, this area was selected for the more detailed monitoring using stress waves as described in the next section.

After location of the events, interesting conclusions can be drawn about the attenuation of the structure. In Fig. 4(a) the amplitude of the hits of all events is depicted vs. the distance from the source. The average first hit stands at an amplitude of $54 \mathrm{~dB}$. In Fig. 4(b) the linear fits to the amplitude of each individual event are plotted. Attenuation can be calculated by the slope of each line. Averaging of the slopes of the events recorded from the whole structure results in -7.02 $\mathrm{dB} / \mathrm{m}$. It is seen that any "hit" propagates at least $1.5 \mathrm{~m}$ before being reduced below the threshold level (40 dB). Therefore, they are recorded by at least 2 sensors. This shows that the separation distance of the sensors is adequate for source location in this case. In any case, attenuation is a crucial parameter that should be seriously taken into consideration since in monitoring of most large structures, compromises must be made between the available number of sensors, time restrictions for measurement preparation and the desirable degree of detail of examination. Attenuation is a key parameter to make an adequate decision.

\section{VELOCITY MEASUREMENTS}

In order to make a more detailed examination of the area indicated by $\mathrm{AE}$ activity, wave velocity measurements took place. Concerning concrete, velocity has been studied in respect to 
material quality for many decades (Kaplan, 1959). However, since many parameters, such as the water to cement ratio, aggregate content, porosity and pulse frequency influence the wave propagation (Philippidis and Aggelis, 2005, Punurai et al. 2007), a relationship that holds for any case cannot be obtained (Popovics, 2001). Generally, it is accepted that pulse velocity above $4000 \mathrm{~m} / \mathrm{s}$ indicates high quality, while below $3000 \mathrm{~m} / \mathrm{s}$ suggests poor quality (Naik and Malhotra, 1991). This information about the material seems quite rough; however, in similar cases of large concrete structures, monitoring and repairing action aims to extend the service life for many years or decades. Therefore, even this rough estimation is of great value.

For the velocity measurement, nine AE sensors were used in an arrangement of three parallel arrays of three. The separation distance was $1.5 \mathrm{~m}$, resulting in an examined area of $3 \mathrm{~m}$ by $3 \mathrm{~m}$ (see Fig. 5). The excitation was conducted by pencil lead break near the location of each transducer. Therefore, each time, one sensor was used as trigger for the acquisition and eight as receivers. This way a number of intersected paths were examined, and the results can be considered more representative of the area and more reliable than one single measurement between two points. The velocity was measured by the time of the first detectable disturbance of each waveform. Although surface propagation includes different kinds of waves, with the Rayleigh occupying most of the energy of the excitation, it is straightforward that the first arrival belongs to longitudinal waves which are the fastest type. It is mentioned that the excitation at each point was repeated five times to check repeatability. The waveforms were identical since the excitation of pencil lead break is quite repeatable.

The transit times of the individual paths and the geometry were supplied to suitable tomography program (Kobayashi et al., 2006). This way the visualization of the velocity structure was obtained, as seen in Fig. 6. The tomogram supplies the information of which parts 
of the surface area exhibit lower velocity than others. From this figure, it is seen that within the area of $9 \mathrm{~m}^{2}$, considerable discrepancies of wave velocity emerge. These discrepancies correspond to different degree of inhomogeneity. Specifically, a zone approximately in the center of the selected area exhibited velocity of less than $2500 \mathrm{~m} / \mathrm{s}$, indicating poor quality, while other parts exhibited velocity higher than $4000 \mathrm{~m} / \mathrm{s}$. As stated above concerning AE activity, the events may propagate through different parts of the structure or reinforcement and their exact source could be concrete cracks, delaminations of different layers (e.g. asphalt on concrete) or friction between the tendon ducts and matrix concrete. As to the velocity measurements though, propagation took place only through the surface layer of concrete. Therefore, the velocity is characteristic of the concrete material itself indicating low quality or extensive damage on that specific area. It is reminded that the general condition of the structure was considered satisfactory after visual observation. Therefore, the low velocity is attributed to a subsurface defect.

The depth cannot be easily determined though. Concerning Rayleigh waves, it is accepted that the penetration depth is approximately similar to the wavelength (Aggelis and Shiotani, 2007). In this case however, the first arrival used to measure velocity corresponds to the longitudinal wave which is in any case faster than Rayleigh or shear waves. Therefore, it is not straightforward how deep is the surface layer characterized by this velocity. Concerning Rayleigh propagation, typical velocities for the bottom part of Fig. 6 were around $2500 \mathrm{~m} / \mathrm{s}$, corresponding to longitudinal velocity certainly higher than $4000 \mathrm{~m} / \mathrm{s}$ (assuming a typical Poisson ratio of 0.2 ). Although this implies good quality, the determination of Rayleigh velocity was not always possible due to severe attenuation and distortion of the waveform, especially for paths at the top of Fig. 6 . This was because there was no characteristic point to use as reference 
for Rayleigh wave measurement (Qixian and Bungey, 1996). This is shown in Fig. 7. This is an example of waveforms acquired after excitation at the center sensor. The excitation waveform has been reduced by a factor of 10 to fit in the graph. For sensors 4-9 the Rayleigh burst is easily identified, and the measurement of its velocity can be conducted by a reference point (i.e. the first positive peak). However, for sensors 1-3 which correspond to the top of Fig. 6, no Rayleigh part is identified and the energy is much lower. This again shows that the propagating zone was disrupted by a discontinuity. Using the Rayleigh velocity of $2500 \mathrm{~m} / \mathrm{s}$ and the major frequency component of $50 \mathrm{kHz}$ (see Fig. 8), the wavelength is calculated to approximately $50 \mathrm{~mm}$. Therefore, since the Rayleigh component was not visible through some paths, this should be due to a weak material zone or discontinuity that extends very close to the surface (even closer than $50 \mathrm{~mm}$ ). From Fig. 8 it is concluded that the major frequency component of around $50 \mathrm{kHz}$ survives the propagation while attenuation severely diminishes the higher frequency content introduced by the pencil lead break. The characterization depth using surface wave examination (including Rayleigh and longitudinal components) needs further study, which is currently undertaken.

\section{CONCLUSIONS}

In this paper, the suitability of acoustic emission and ultrasonic testing to monitor large concrete structures is presented. The $\mathrm{AE}$ technique was initially used to select the most deteriorated area. The subsequently conducted ultrasonic examination exhibited very low velocities confirming that the area indicated by AE activity was actually deteriorated. This shows the potential of $\mathrm{AE}$ as a global monitoring technique for examination of large volumes using a 
limited number of sensors. Even if AE indices or parameters (the number of AE hits in this case) cannot be directly correlated with the degree of damage, they suggest which part of the structure needs further and detailed investigation. Consecutively, wave velocity measurements were conducted allowing a more adequate evaluation through established correlations between velocity and concrete quality. As to the $\mathrm{AE}$ observed, concrete cracks, delaminations of different layers (e.g. asphalt on concrete) or friction between the tendon ducts and matrix concrete are possible origins. Follow-up investigations focusing on this weak area should clarify the source. This sequential investigation which started with AE activity and followed by measurements of ultrasonic velocity is useful as a first step to characterize the quality of large-scale concrete structures. 


\section{REFERENCES}

Aggelis, D. G., Shiotani, T., (2007), "Repair evaluation of concrete cracks using surface and through-transmission wave measurements.” Cement and Concrete Composites, 29(9), 700-711.

Colombo, S., Forde, M.C., Main, I.G. and Shigeishi, M., (2005). "Predicting the ultimate bending capacity of concrete beams from the "relaxation ratio" analysis of AE signals.” Construction and Building Materials 19(10), 746-754.

Grosse, C., Reinhardt, H. and Dahm, T., (1997). "Localization and classification of fracture types in concrete with quantitative acoustic emission measurement techniques.” NDT E Int 30(4), 223-230.

Gudra, T. and Stawinski, B., (2000). "Non-destructive characterization of concrete using surface waves.” NDT\&E INT 33(1), 1-6.

Kaplan, M.F., (1959). "The effects of age and water/cement ratio upon the relation between ultrasonic pulse velocity and compressive strength.” Mag. Concr. Res. 11(32), 85- 92.

Kobayashi, Y., Shiojiri, H. and Shiotani, T., (2006). "Damage identification using seismic travel time tomography on the basis of evolutional wave velocity distribution model”, Proc. Structural Faults and Repair-2006 (Ed. M. Forde), June 13-15, Edinburgh. (in CD).

Malhotra, V. M. and Carino N. J., eds., (1991). CRC Handbook on Nondestructive Testing of Concrete, CRC Press, Florida.

Naik, T. R. and Malhotra V. M., (1991). The ultrasonic pulse velocity method. CRC Handbook on Nondestructive Testing of Concrete, V. M. Malhotra and N. 
J. Carino, eds., CRC Press, Florida., 169-188.

Ohtsu, M., Uchida, M., Okamoto, T. and Yuyama, S., (2002). "Damage assessment of reinforced concrete beams qualified by acoustic emission.” ACI Structural Journal 99(4), 411-417.

Philippidis, T.P. and Aggelis, D.G., (2005). "Experimental study of wave dispersion and attenuation in concrete.” Ultrasonics 43(7), 584-595.

Popovics, S., (2001). “Analysis of the Concrete Strength versus Ultrasonic Pulse Velocity Relationship.” Materials Evaluation 59(2), 123-129.

Punurai, W., Jarzynski, J., Qu, J., Kurtis, K.E. and Jacobs, L.J., (2007). “Characterization of dissipation losses in cement paste.” Mechanics Research Communications 34(3), 289-294.

Qixian, L., Bungey, J. H., (1996), “Using compression wave ultrasonic transducers to measure the velocity of surface waves and hence the dynamic modulus of elasticity of concrete.” Construction and Building Materials, 10(4), 237-242.

Schechinger, B. and Vogel, T., (2007). "Acoustic emission for monitoring a reinforced concrete beam subject to four-point-bending.” Construction and building materials 21(3), 483-490.

Shiotani, T., (2006). "Evaluation of long-term stability for rock slope by means of acoustic emission technique.” NDT \& E International 39(3), 217-228.

Shiotani, T., Aggelis, D., G., Makishima, O., (2007). “Global monitoring of concrete bridge using acoustic emission.” Advances in Acoustic Emission 2007, (ed. K. Ono), pp. $402-407$ (Proc. 6 ${ }^{\text {th }}$ International Conference on Acoustic Emission, Lake Tahoe, Nevada, USA, October 29th-November 2nd, 
2007).

Shiotani, T., Fujii. K., Aoki, T. and Amou, K., (1994). "Evaluation of progressive failure using AE sources and improved b-value on slope model tests.” Prog. Acoust. Emiss VII(7), 529-534. 


\section{Figure Captions}

Fig. 1 Representation of the crane passing over the bridge and sensors location.

Fig. 2 Time history of strain at the center and cumulative AE hits during crane passage.

Fig. 3 Number of hits per channel and distance.

Fig. 4 (a) Hit amplitude vs. distance from event source, (b) individual attenuation slope for different events.

Fig. 5 Sensor arrangement for surface wave measurements.

Fig. 6 Velocity structure of the bottom surface of the bridge concrete. The positions of the transducers are indicated by , and the examined wave paths by dashed lines.

Fig. 7 Typical waveforms after excitation at the center position of Fig. 6.

Fig. 8 Typical Fast Fourier transforms for three distances from the excitation. 


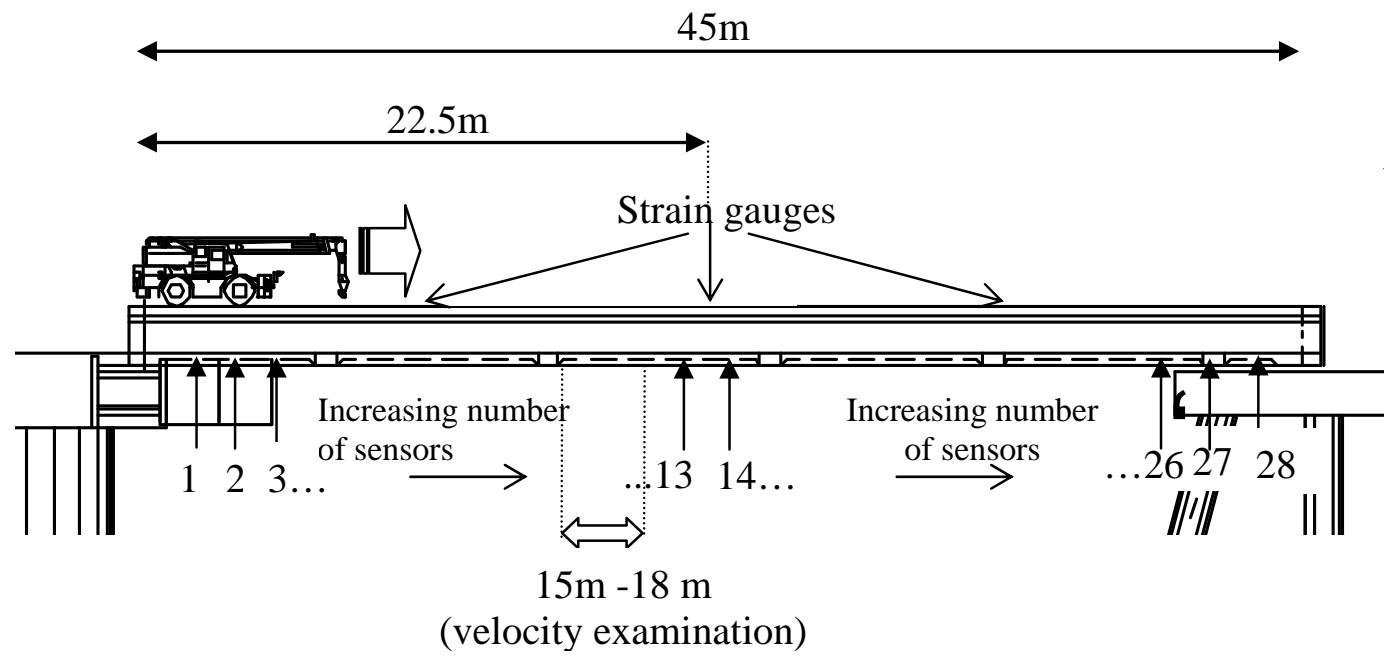

Fig. 1. Representation of the crane passing over the bridge and sensor location. 


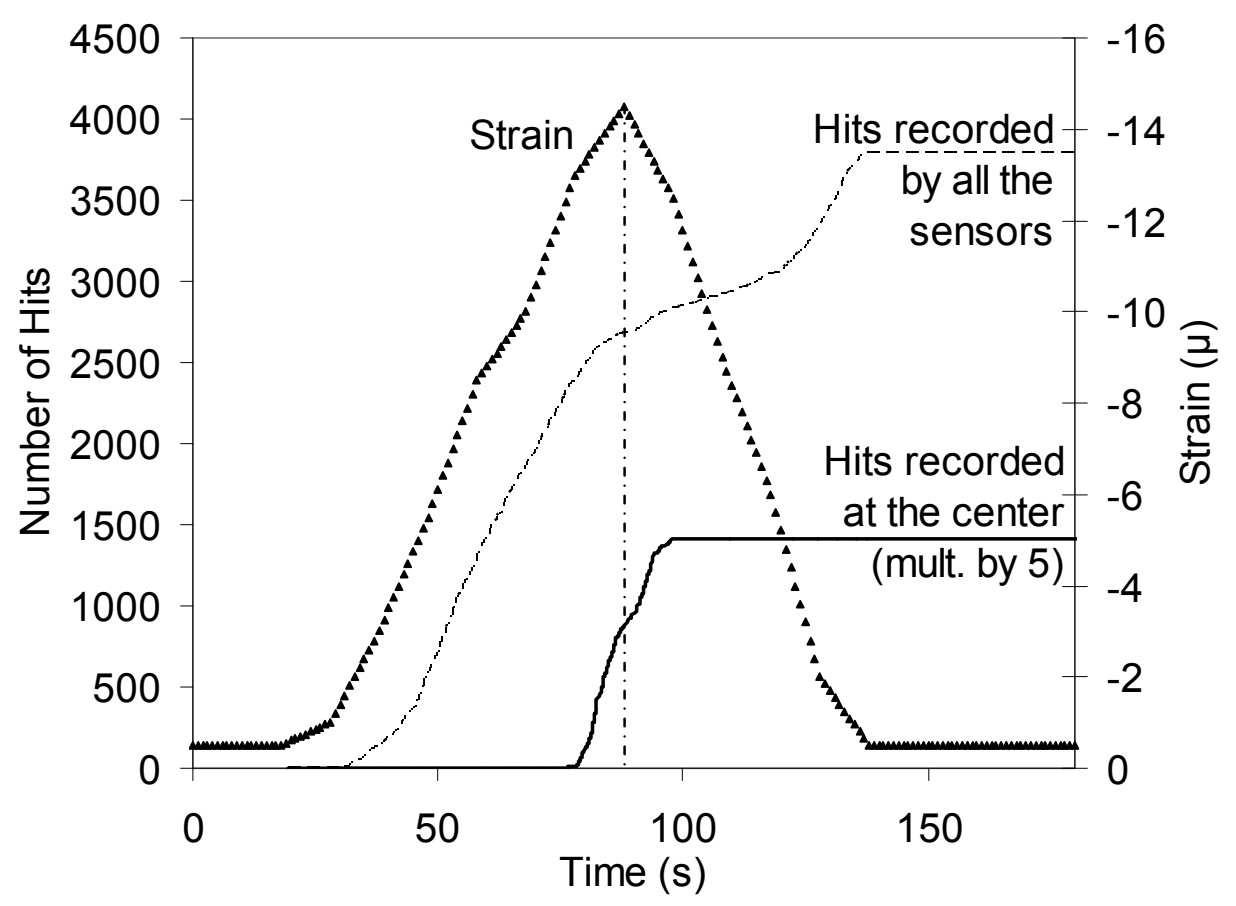

Fig. 2. Time history of strain at the center and cumulative AE hits during crane passage. 


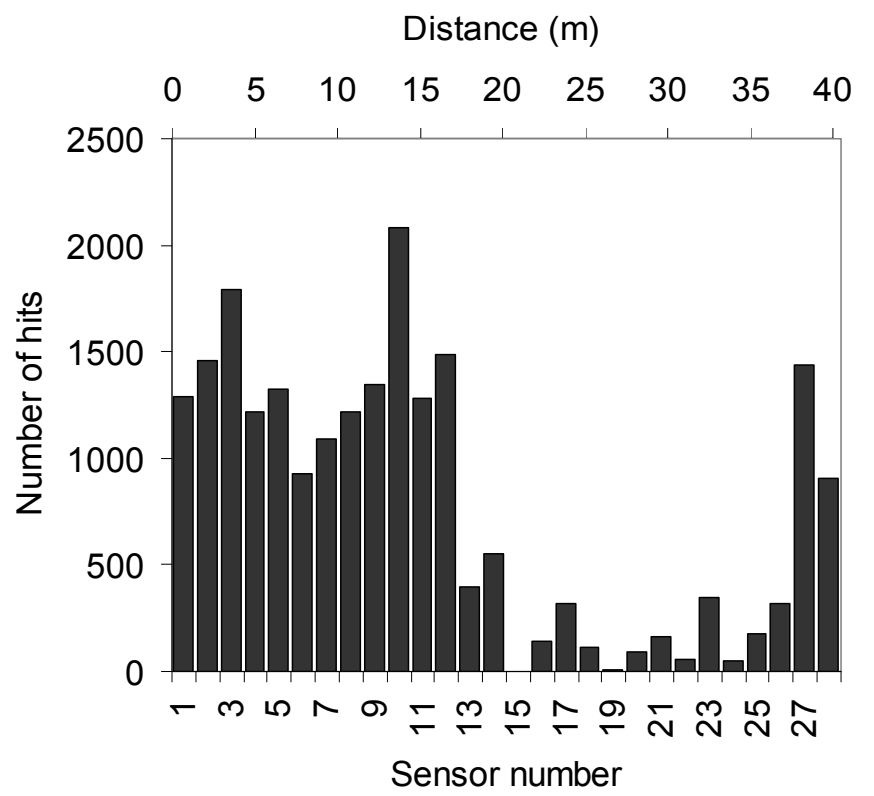

Fig. 3. Number of hits per channel and distance. 


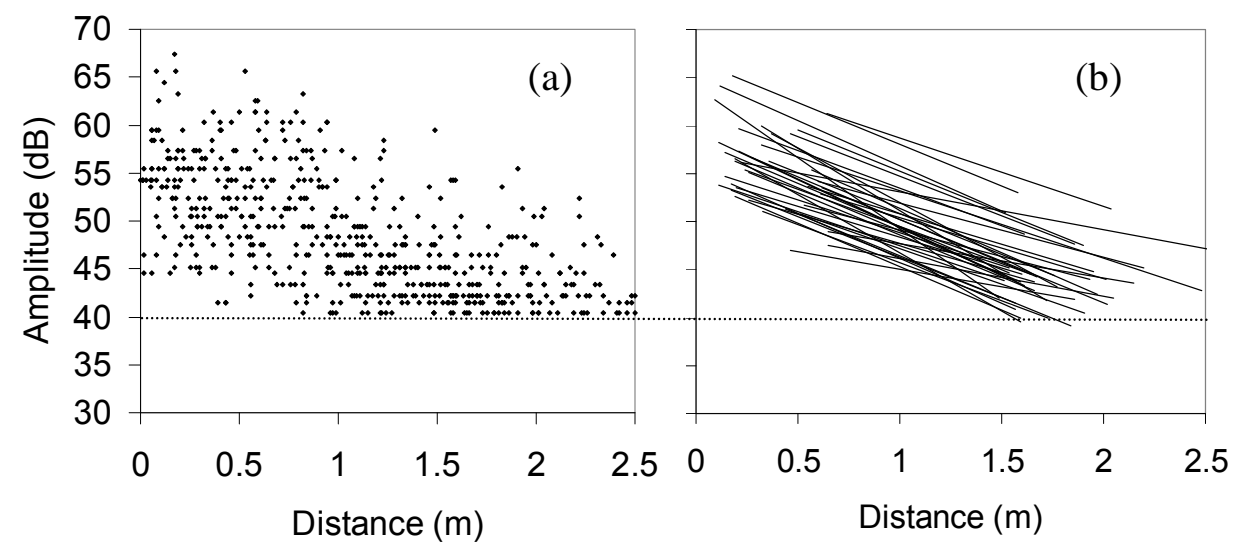

Fig. 4. (a) Hit amplitude vs. distance from event source, (b) individual attenuation slope for different events. 


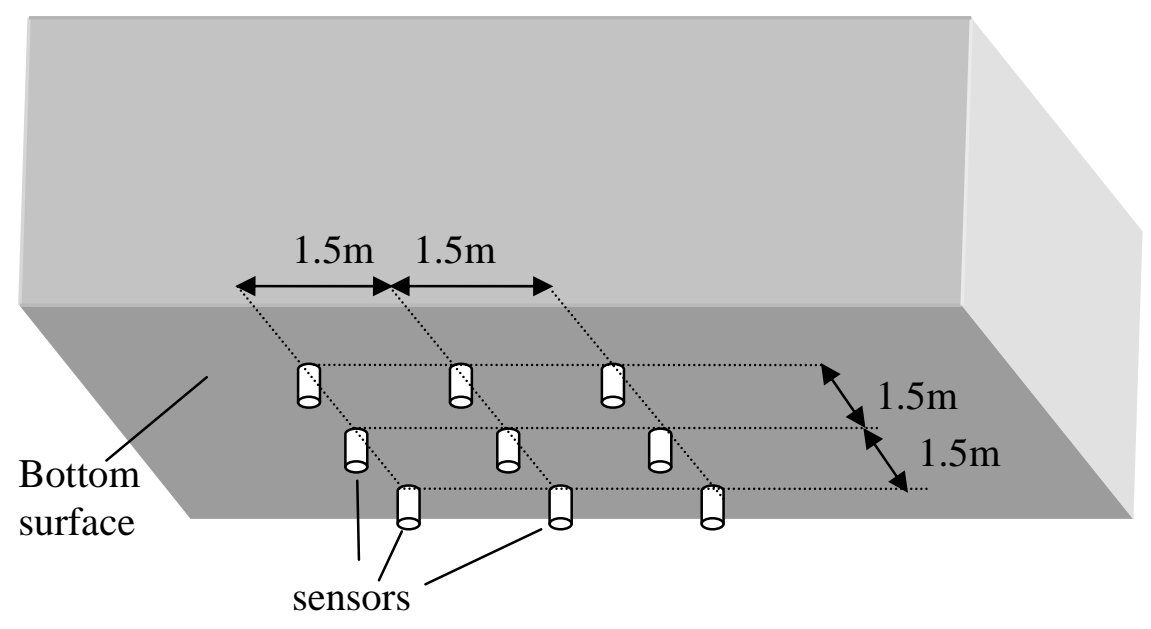

Fig. 5. Sensor arrangement for surface wave measurements. 


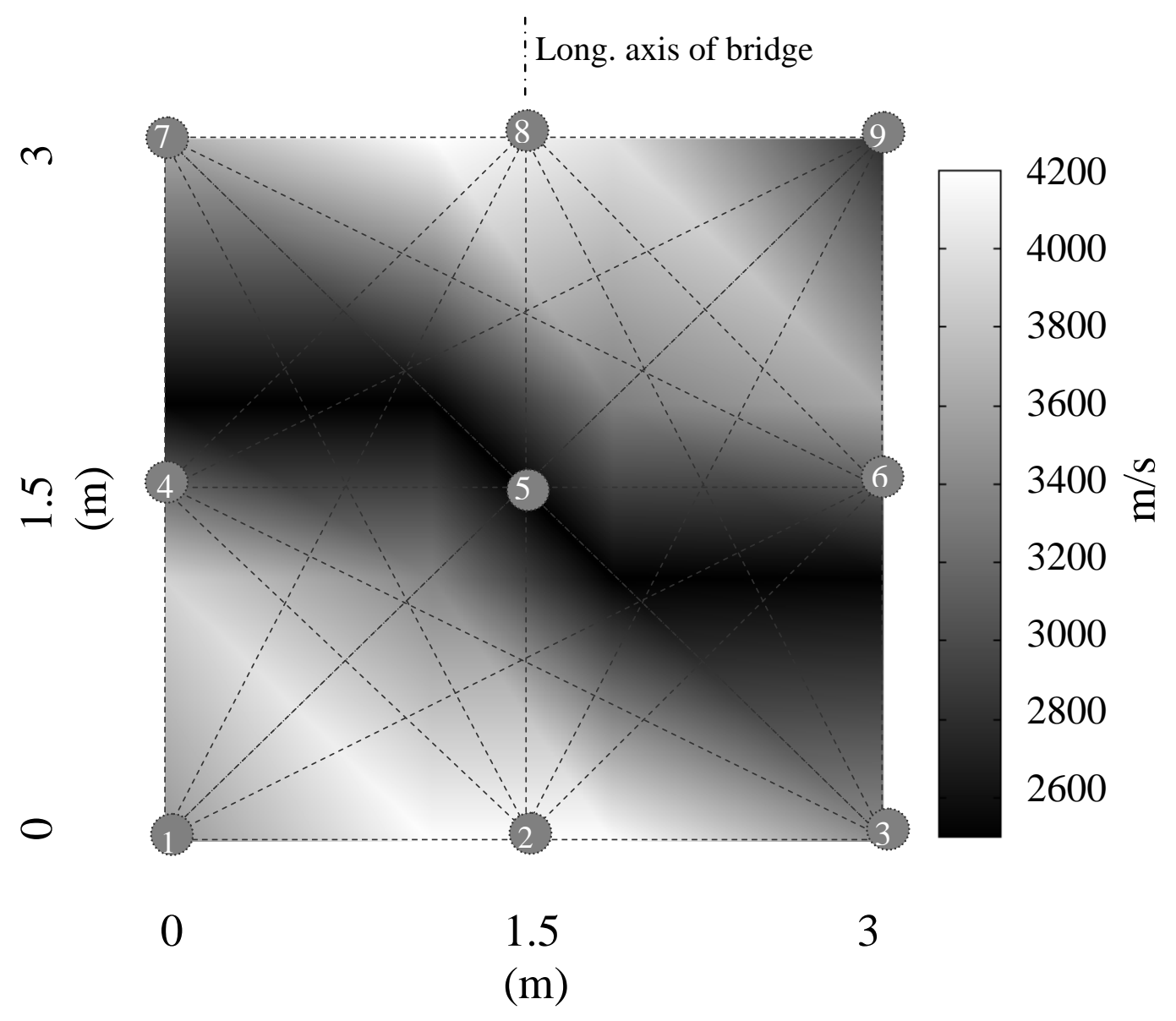

Fig. 6. Velocity structure visualization of the bottom surface of the bridge concrete. The positions of the transducers are indicated by 0 , and the examined wave paths by dashed lines. 


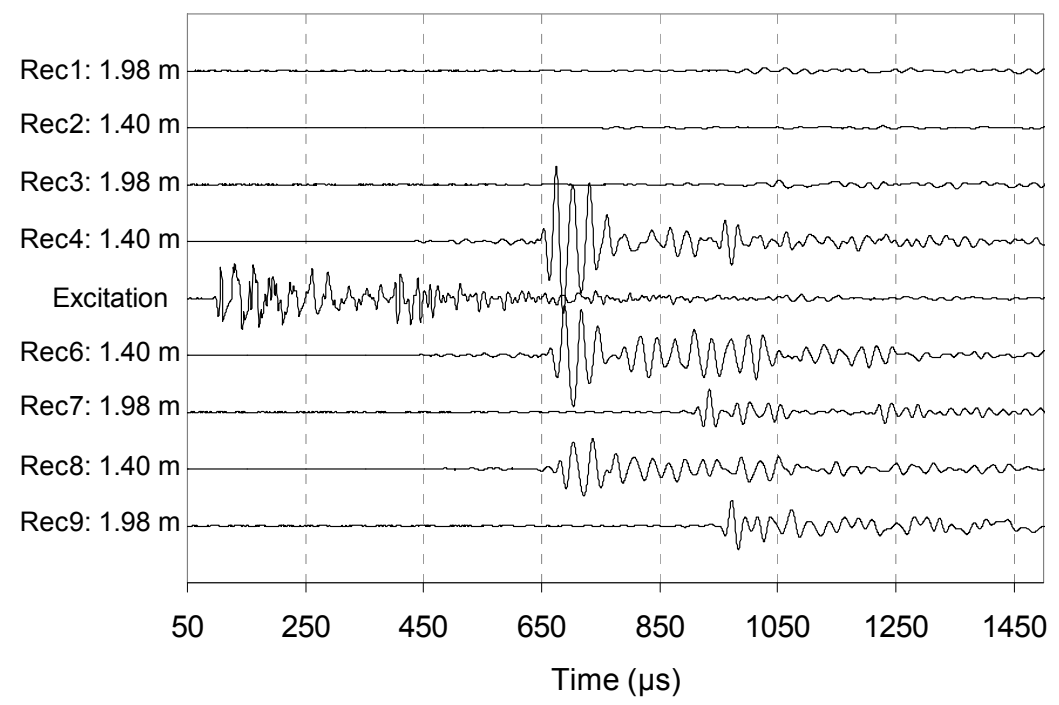

Fig. 7 Typical waveforms after excitation at the center position of Fig. 6. 


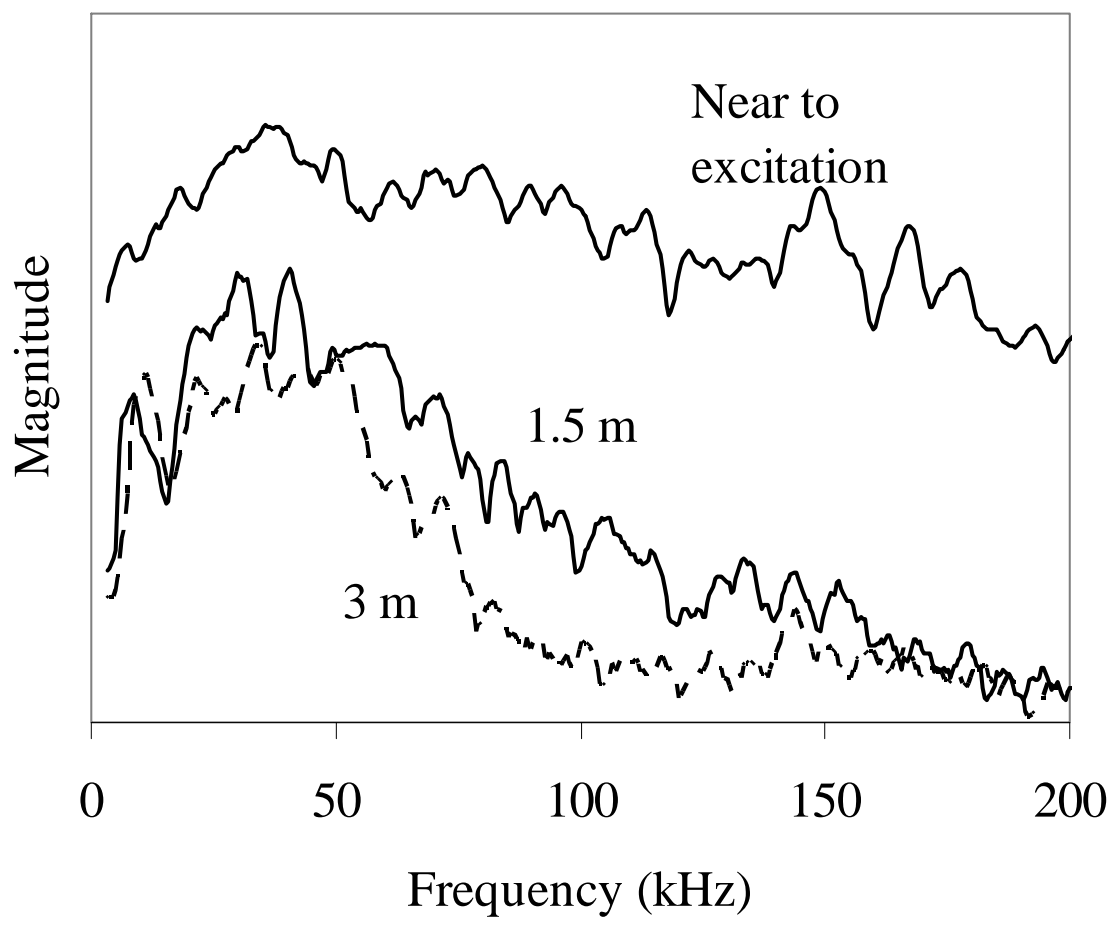

Fig. 8 Typical Fast Fourier transforms for three distances from the excitation. 